This item was submitted to Loughborough's Research Repository by the author.

Items in Figshare are protected by copyright, with all rights reserved, unless otherwise indicated.

\title{
A survey of the design needs of older and disabled people
}

PLEASE CITE THE PUBLISHED VERSION

\section{PUBLISHER}

(C) Taylor \& Francis

\section{VERSION}

VoR (Version of Record)

\section{PUBLISHER STATEMENT}

This work is made available according to the conditions of the Creative Commons Attribution-NonCommercialNoDerivatives 4.0 International (CC BY-NC-ND 4.0) licence. Full details of this licence are available at: https://creativecommons.org/licenses/by-nc-nd/4.0/

\section{LICENCE}

CC BY-NC-ND 4.0

\section{REPOSITORY RECORD}

Oliver, Ruth, Diane E. Gyi, J. Mark Porter, Russell Marshall, and Keith Case. 2019. "A Survey of the Design Needs of Older and Disabled People”. figshare. https://hdl.handle.net/2134/18077. 
In M. A. Hanson (Ed.), 'Contemporary Ergonomics 2001', the Proceedings of the Annual Conference of the Ergonomics Society (pp. 365-370).

Royal Agricultural College, Cirencester, UK: Taylor \& Francis.

Also published in Ergonomics Abstracts, No 175658, 2001.

\title{
A survey of the design needs of older and disabled people
}

\author{
Ruth Oliver ${ }^{1}$, Diane Gyi ${ }^{1}$, Mark Porter ${ }^{1}$, Russ Marshall ${ }^{1}$, Keith Case $^{2}$ \\ ${ }^{1}$ Department of Design and Technology, \\ ${ }^{2}$ Wolfson School of Mechanical and Manufacturing Engineering, \\ Loughborough University, Loughborough, Leics., LE11 3TU, UK
}

\begin{abstract}
The challenges facing design teams with respect to older and physically disabled people are only now beginning to be addressed, largely due to the fact that the population is ageing. In order for designers to consider the needs of these people and design inclusively, it is necessary to understand the requirements and preferences that are experienced in Activities of Daily Life (ADL), as people interact with everyday products, environments, and systems. This paper presents the results of a survey into the needs of older and disabled people today. The results show that, despite advances in technology and design, participants still have difficulty performing the everyday activities that most of us take for granted.
\end{abstract}

\section{Introduction}

In the literature there are a number of studies investigating the problems with Activities of Daily Life (ADL) that older people experience (Weber et al, 1989; Ashworth et al, 1994; Department of Trade and Industry - DTI, 2000). However, none really address what these people really want to be able to do, or need to be able to do more easily.

The survey detailed in this paper forms part of an Engineering and Physical Sciences Research Council (EPSRC) 3-year project under the EQUAL initiative, aimed at Extending QUAlity Life. This project aims to develop a computer design tool to help designers 'design for all'. The survey detailed here aimed to get a broad range of views from older and disabled people as to what activities cause them problems, and what they would like to be able to do more easily. The results will direct the next phase of the research, the selection of tasks to focus the collection of task-specific data for the computer tool.

\section{Method}

A semi-structured questionnaire was used to investigate these issues and provide the interviewer with a frame to work within. Detailed responses to the questions were noted, 
and a scale was used by the interviewer to facilitate assessing the level of difficulty (Table 1). In this way both quantitative and rich qualitative data were collected.

Table 1. Interviewer's scale (with description) used to assign rating based on participants' responses

\begin{tabular}{ll}
\hline Scale point & Description \\
\hline Easily & No problems performing activity \\
\hline Some problems & $\begin{array}{l}\text { Some difficulty but no need for assistive devices (such as levers, } \\
\text { bath chairs, and so on) }\end{array}$ \\
\hline Some help & $\begin{array}{l}\text { Basic assistive devices needed (e.g. tap levers, stool in bath/ } \\
\text { shower) }\end{array}$ \\
\hline Considerable help & $\begin{array}{l}\text { Assistance from another person and/or complex device needed } \\
\text { (e.g. hoist for bath or toilet) }\end{array}$ \\
\hline Impossible & Participant unable to perform activity \\
\hline Not done & $\begin{array}{l}\text { Activity not attempted for reasons other than physical difficulty } \\
\text { (e.g. lack of interest, necessary equipment not owned) }\end{array}$ \\
\hline
\end{tabular}

The interviews were approximately 20 minutes long and mostly conducted face-toface, although some were by telephone. It was felt that a personal approach would result in higher response rates than postal questionnaires, and remove the possibility of any practical problems for participants completing the questionnaires themselves. This approach also allowed for discussion of interesting points raised, clarification of any misunderstandings, and demonstration of any particular difficulties.

The questionnaire was divided into seven sections, each concentrating on a different area (Table 2). The different sections were designed to be specific and provide focus, rather than asking very broad, general questions. Tasks were selected to be generic in the movements required to complete the task. For example, one question in the kitchen section was 'how do you manage with lifting a small saucepan onto the back hob?'. This asks about a specific activity, but it was felt that the answers would be similar to those for other activities that require lifting and reaching an item of a similar weight at about waist height.

Each section ended with a question asking if there was anything that participants' would really like to be able to do, or do more easily (within the limitations of their disability), if the equipment or environment were designed differently. This information was important in order for the research team to understand what the priorities for older and disabled people are when it comes to design improving quality of life.

It was intended that 50 people be interviewed ( 25 men and 25 women). The participants were not intended to be representative of the population as a whole, but to provide valuable information as to the problems and needs of people across a wide range of age, abilities and disabilities. Broadly, the breakdown was as follows: ten aged 18-32 years (disabled), ten aged 33-47 years (disabled), ten aged 48-62 years (disabled), ten aged 63 years + (disabled), and ten aged 63 years + (able-bodied). These strata were to ensure a spread of ages within the sample.

Participants were personally recruited from local clubs for disabled or older people and by the handing out of fliers at the Motorbility Roadshow, held at Donnington Park in June 2000. Informed consent was obtained from all participants prior to the interview commencing. 
Analysis involved taking counts of the number of participants reporting the same level of difficulty with the same tasks, and also the number of similar comments being made by different participants. The main findings are presented in this paper.

Table 2. Structure of the interview questionnaire

\begin{tabular}{ll}
\hline Section & Detail \\
\hline Personal details & $\begin{array}{l}\text { Age, gender, home type, mobility at home/outside, reliance } \\
\text { on others, use of stairs, main problems due to disability }\end{array}$ \\
\hline Kitchen & $\begin{array}{l}\text { Using hob, oven, taps, doing washing-up, washing clothes, } \\
\text { reaching high shelves, filling kettle }\end{array}$ \\
\hline Bathroom & Using bath, shower, toilet \\
\hline General household & Opening/closing windows, doors, plugs into/out of sockets \\
\hline General away from home & $\begin{array}{l}\text { Into/out of cars, using buses, trains, cash machines, getting } \\
\text { petrol, shopping in large shops }\end{array}$ \\
\hline Work (where applicable) & Access, movement within area, reaching \\
\hline Leisure & Activities undertaken, using leisure centres, garden \\
\hline
\end{tabular}

\section{Results}

\section{Personal details}

To date interviews have been conducted with 43 older and disabled people (18 men aged 21-99 years, 25 women aged 21-82 years). This includes younger disabled people, 5 people over 63 years with no specific impairments, and 10 older people with disabilities.

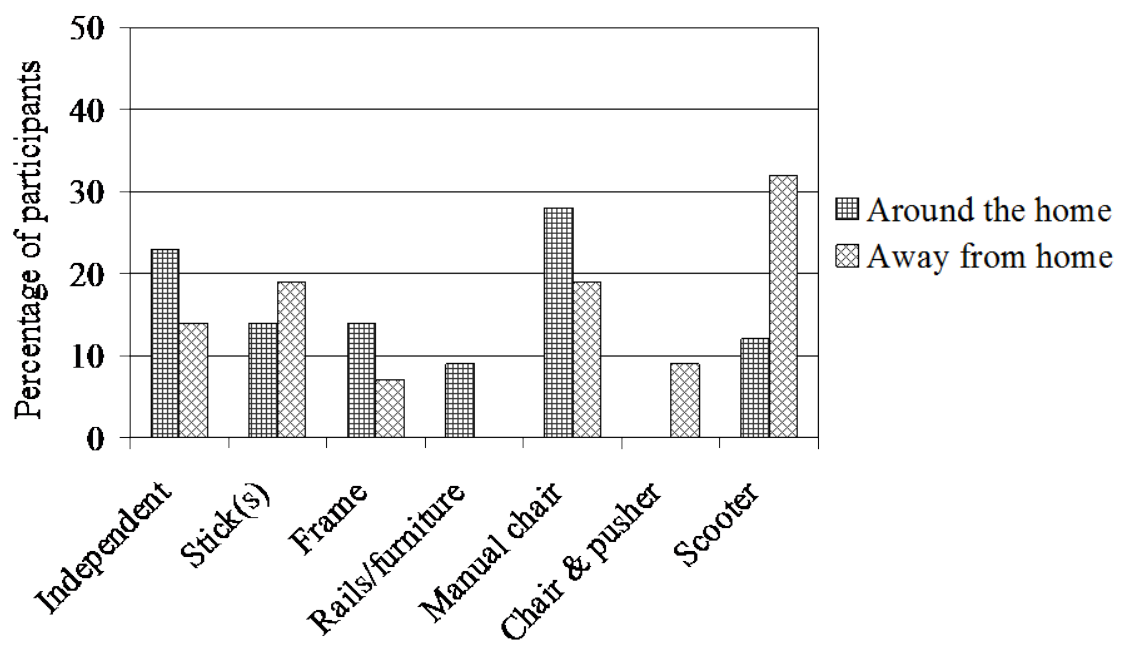

Figure 1. Percentage of participants using various modes of mobility within the home and away from home $(n=43)$

The results show that, not surprisingly, most people wanted to maintain independence and perform the every day activities that other people take for granted, and all but 2 participants lived at home. Figure 1 shows the number of participants reporting different 
levels of mobility and any assistance needed to be mobile (for example a stick, or wheeled frame), both in the home and away from home. Seventeen participants were actually in a wheelchair for the majority of the time. Around the home $23 \%$ of all participants were fully independent whilst only $14 \%$ were when away from home. This pattern of reduced independence in mobility is repeated throughout Figure 1.

\section{Bathroom tasks}

Figure 2 shows that $42 \%$ of participants found it impossible to use their bath or needed considerable help, for example another person and/or a hoist. Two participants did not use the bath for fear of slipping and falling, and four participants could only use the bath with two handrails fitted. Nine participants had a seat to assist them in using the shower. The three participants needing 'considerable help' to use the toilet needed another person and a hoist to lift them on and off the toilet.

\section{Kitchen tasks}

Figure 3 details the kitchen tasks that participants required considerable help with or found impossible. Activities that involved less lifting and reaching resulted in fewer problems (such as washing up small items). Many coping strategies were mentioned, including sitting to do tasks (5 participants), sliding heavy items along surfaces rather than lifting (7 participants), moving heavy items in stages - from worktop to stool, from stool to oven (3 participants), and sitting/kneeling on the floor for low tasks, such as using the oven (2 participants).

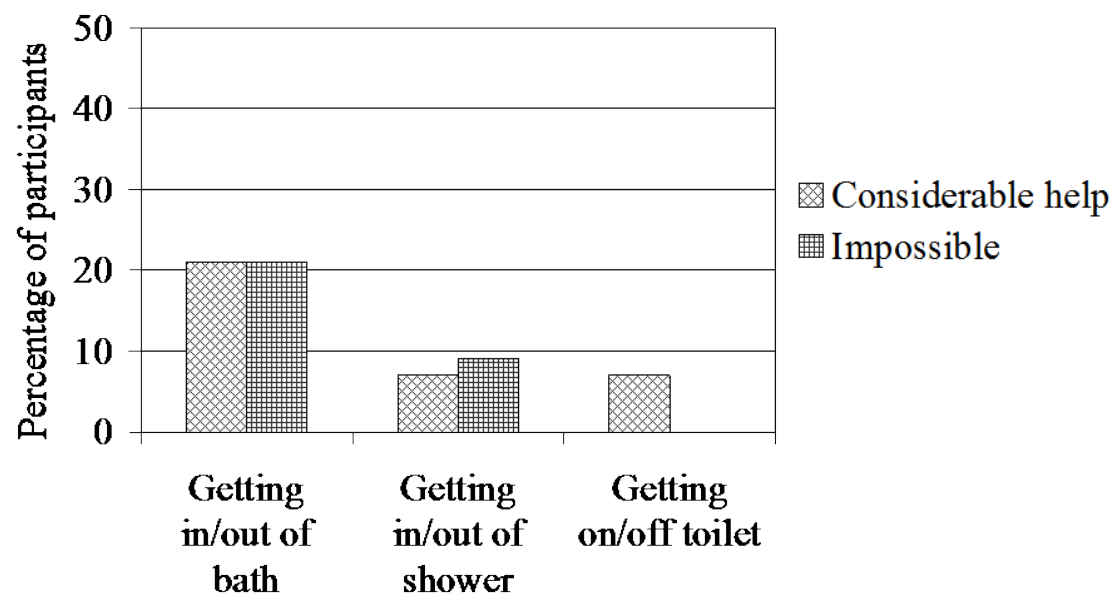

Figure 2. Percentage of participants requiring considerable help or unable or complete bathroom tasks 


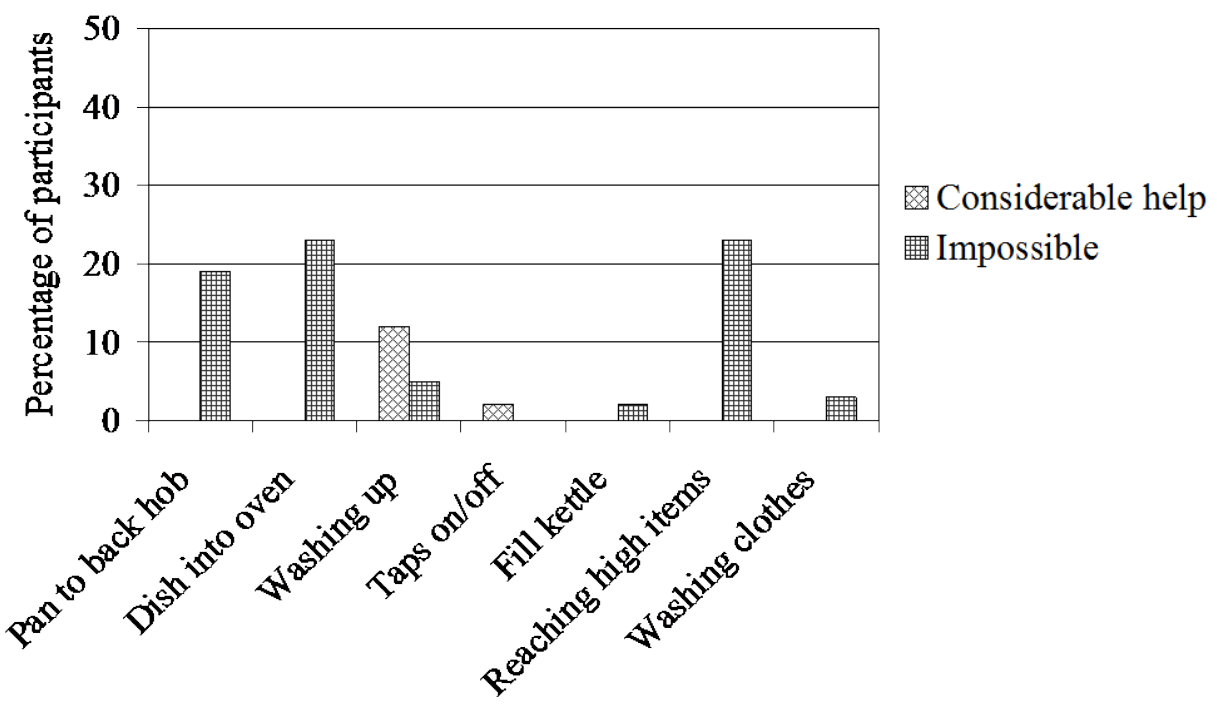

Figure 3. Percentage of participants requiring considerable help or unable or complete kitchen tasks

\section{General household and general away from home}

Participants reported that opening and closing windows only caused problems if they were high (14 participants) or too heavy (2 participants). Opening and closing doors caused problems if too narrow for a wheelchair (2 participants).

With regard to transport, 8 participants reported needing considerable help getting in and out of cars. Buses were inaccessible to scooters (14 participants), whilst lower, 'kneeling' buses were easier for ambulant participants. Only 19 participants had ever tried to use trains, with the remainder saying that they were put off by the difficulties involved due to their disability, or that they had alternative means of transport. Cash machines were often at the wrong height (13 participants). Shopping in large shops was possible for 38 participants, but help was needed with reaching and carrying items (6 participants).

\section{Work and Leisure}

Interestingly, 24 participants were of working age (18-65 years of age), but only 7 were actually working. No problems were mentioned by these individuals with the working environment, due to the companies having made any necessary alterations prior to them starting work.

Participants were involved in a wide range of leisure activities, with a surprisingly high number (20 participants) saying that there was nothing that they wanted to do that they were unable to do. Access caused the most problems, with problems with access to swimming (8 participants), cinema (3 participants), and going on holiday/to other peoples' houses (5 participants).

\section{Contribution of the data to the main study}

The results of this survey will be used to inform the collection of detailed, task specific, data from 100 individuals for the next stage of the project. Access issues resulted in the 
highest number of activities that people most wanted to be able to do, or do more easily (27 participants), but access is beyond the scope of this investigation, with the focus being more on the design of products and systems.

Kitchen tasks contain many generic actions that are applicable to other ADL: reaching high (impossible for $23 \%$ ), bending (impossible for $23 \%$ to use oven, and $3 \%$ to use washing machine) and lifting (impossible for $19 \%$ to lift a pan). Being able to use the oven was also something that 9 participants most wanted to be able to do. It was therefore decided that the detailed data collection phase would involve the lift-bend-reach activities concerned with cooking and using an oven. The activities involved in this task are also suitable for modelling on the computer.

\section{Discussion and conclusions}

This study, despite the small sample size, supports the findings of similar studies (such as DTA, 2000) that older and disabled people experience many difficulties in what should be simple ADL. A person unable to cook for themselves, or dress and toilet themselves clearly must rely on the assistance of others. This, along with the fact that the population is ageing (Sandhu, 1997), shows that there is a potential market for products designed with the needs of older and disabled people in mind.

Looking at the overall difficulty participants experienced, only 2 participants could accomplish all the tasks they were questioned about easily or without needing any assistance. At the other extreme, 4 participants needed considerable help or found some tasks impossible. A further 7 participants reported needing considerable help or found some tasks impossible in all but one area of ADL asked about.

People have coping strategies, but the division between managing with a struggle and failure is wide. The number of participants reporting that they manage 'with considerable help' is far fewer than the number who simply do not do tasks that require such a level of assistance. By encouraging designers to consider the needs of such people when designing products, the number of people able to accomplish tasks easily should increase. This would not only make these peoples' lives easier, but we would know that our own future lives would be easier thanks to the forethought of designers today.

\section{References}

Ashworth, J.B., Reuben, D.B. \& Benton, L.A. 1994, Functional profile of healthy older persons, Age and Aging, 23, 34-39

Department of Trade and Industry Consumer Safety Research. 2000, A study of the difficulties disabled people have when using everyday consumer products. DTI, London

Sandhu, J. 1997, Profit by Design. In I. McLaren (ed.) Proceedings of a conference organised by the British Institute for Design and Disability, London, Oct 1997, (European Institute for Design and Disability), 12-13

Weber, R., Czaja, S. \& Bishu, R. 1989, Activities of daily living of the elders - a task analytic approach. Perspectives: Proceedings of the Human Factors Society $33^{\text {rd }}$ Annual Meeting, Oct. $16^{\text {th }}-20^{\text {th }}$, Denver, Colorado, Volume 1, 182-186 